\title{
Evaluation of supernumerary kidney with fusion using magnetic resonance image
}

\author{
Luciano A. Favorito, Ana Raquel M. Morais \\ Urogenital Research Unit - Departament of Anatomy - Universidade do Estado do Rio de Janeiro - Rio de \\ Janeiro, Brazil
}

Urogenital anomalies are frequent and correspond to 33\% of all congenital anomalies (1). Horseshoe kidney and renal crossed ectopy with fusion are the most frequent renal anomalies (2). Supernumerary kidney is the rarest renal anomaly and it can be encapsulated or totally apart from the original kidney or connected to it by a sheath of connective tissue. Usually the supernumerary kidney is located caudally to the kidney of the same side and is associated with bifid ureter or more infrequently a double ureter $(2,3)$.

There are several reports of supernumerary kidney with fusion (2) but this is the first one described in the literature evaluated with magnetic resonance image.

A female patient of 27 years old presented with left flank pain 3 days duration, dysuria and fever $(100 \mathrm{oF})$. Physical exam of abdomen was inconclusive and ultrasound suggested left duplication of the renal pelvis. Urine exam suggested urinary infection. After the administration of sedatives and antibiotics the patient was submitted to magnetic resonance image (MRI) of abdomen and pelvis (1.5T system - GE Signa Excite). T1 and T2 weighted pre- and post-gadolinium enhancement were obtained.

MRI showed a left moety fused to the upper pole of the supernumerary kidney (Figure-1). The supernumerary kidney showed a defect of rotation and had no dilation of the collecting system. The MRI also showed the presence of individual ureters (Figure-2). After the clinical treatment, the patient got better and was discharged.
There are several theories to explain the occurrence of a supernumerary kidney: a) bifurcation of the ureteral bud with independent penetration of the buds in the metanephrogenic blastema that develop and divide in two kidneys; b) two independent ureteral buds that penetrate the metanephrogenic blastema that divides in two and c) fragmentation of the metanephrogenic blastema due to linear infarcts (3). The supernumerary

Figure 1 - Magnetic ressonance image of abdomen and pelvis of a coronal reconstruction frame in T2. It is possible to observe the fusion of the lower pole of left kidney to the superior pole of the supernumerary kidney.

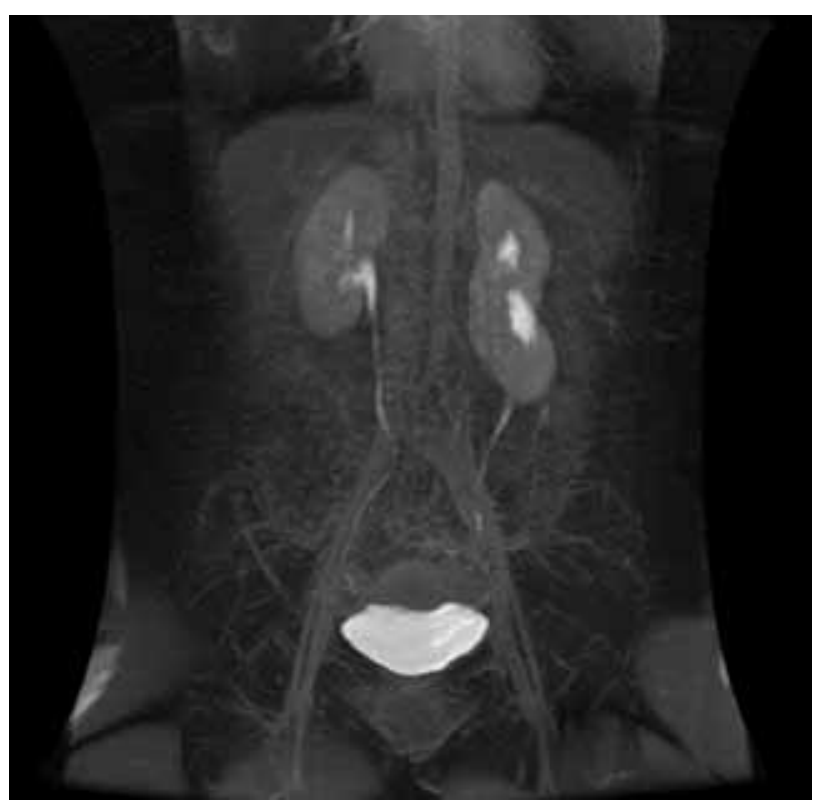


kidney, independently of its origin, does not present characteristic symptoms and in most cases is separated from the same side kidney.

Figure 2 - Magnetic ressonance image of abdomen and pelvis of a sagital reconstruction frame in $\mathrm{T} 2$. It is possible to observe the two independent collector systems without dilation with two ureters running to the bladder.

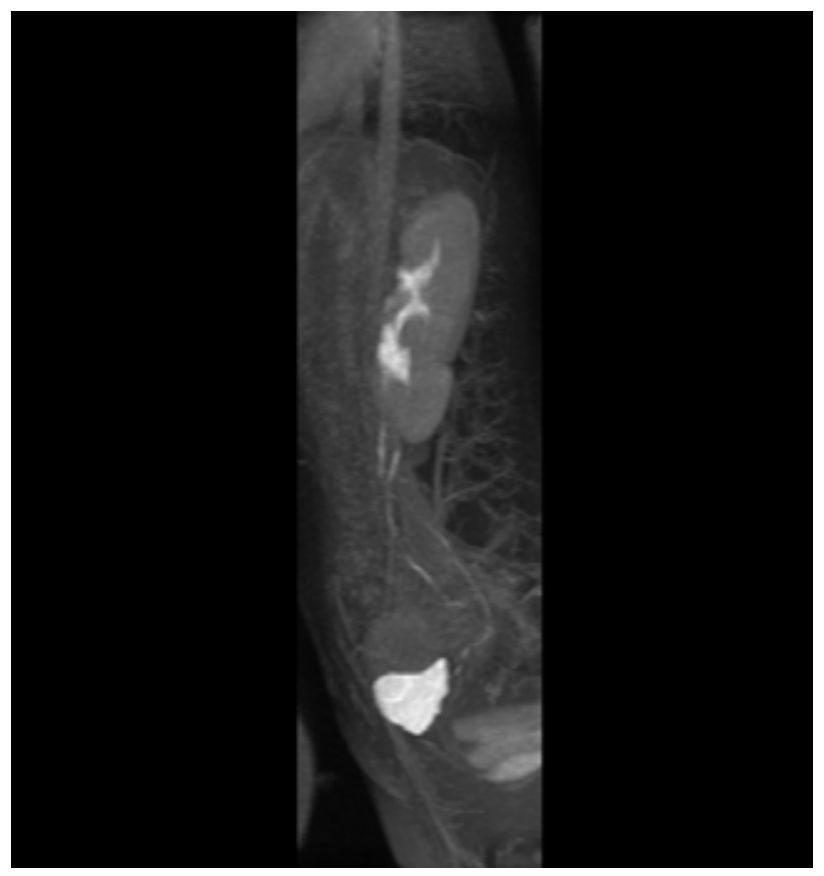

The occurrence of supernumerary kidney with fusion and independent ureter is an extremely rare anomaly, and there are no previous reports of the evaluation of this anomaly with MRI. In the present case, the supernumerary kidney is connected to the same side kidney apparently by a portion of parenchyma and not by connective tissue and has an independent ureter that runs to the bladder, making this case even more rare and special.

\section{REFERENCES}

1. Favorito LA, Cardinot TM, Morais AR, Sampaio FJ: Urogenital anomalies in human male fetuses. Early Hum Dev. 2004 79: 41-7.

2. Sthephens FD, Smith ED, Hutson JM: Normal embriology of the upper urinary tract and kidneys. Congenital anomalies of the kidney, urinary and genital tracts. London: Martin Dunitz; 2002. p. 283-92.

3. Koureas AP, Panourgias EC, Gouliamos AD, Trakadas SJ, Vlahos LJ: Imaging of a supernumerary kidney. Eur Radiol. 2000; 10: 1722-3.
Correspondence address:

Dr. Luciano Alves Favorito Rua Professor Gabizo 104/201 - Tijuca Rio de Janeiro, RJ, 20271-320, Brazil Fax: + 5521 3872-8802 E-mail: lufavorito@yahoo.com.br 